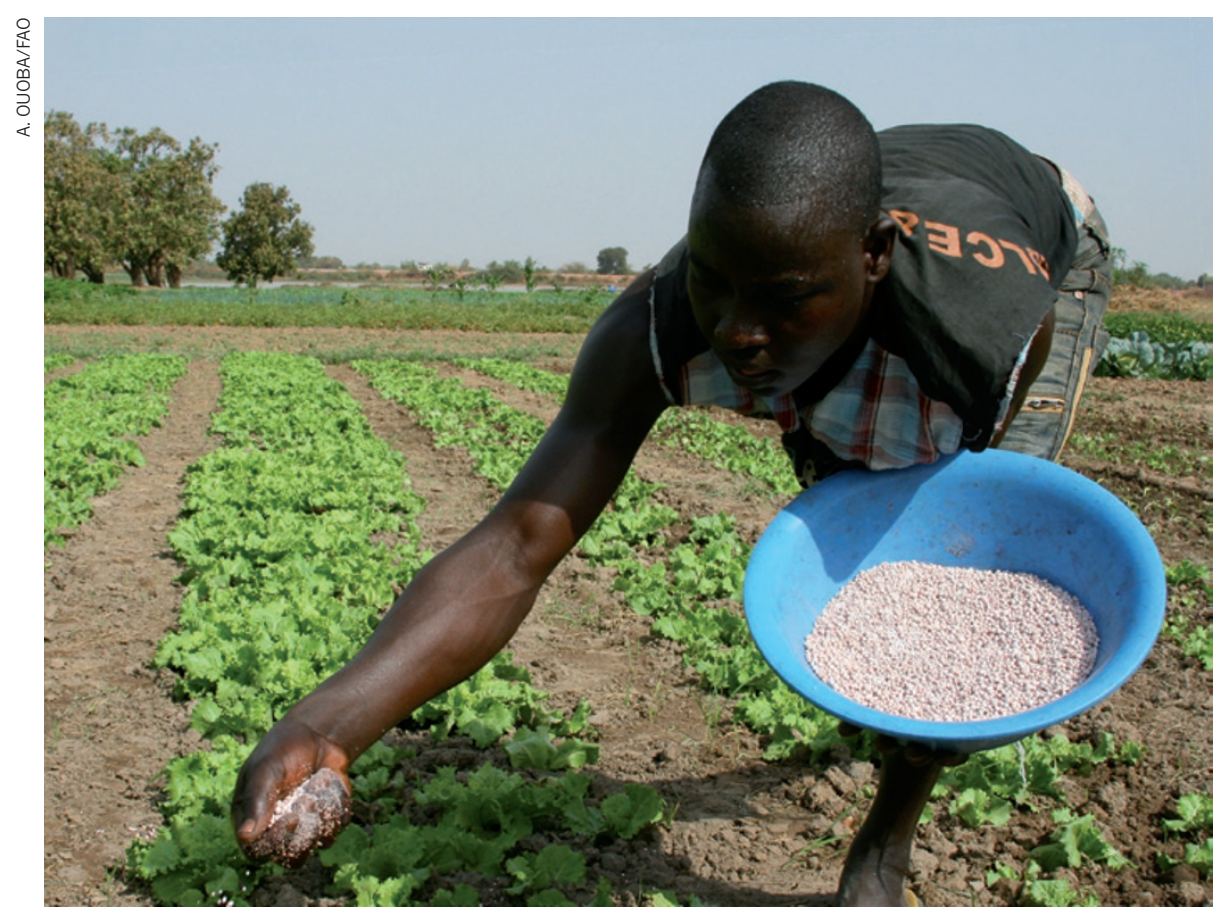

Planting crops that are drought resistant could enable farmers to use less water and fertilizer.

\title{
Preventing hunger: Biotechnology is key
}

\section{If African countries can't plant genetically modified crops to produce more and healthier food, vulnerable populations will be at risk, argues Calestous Juma.}

$\mathrm{T}$ o survive the droughts, wars and other major causes of famine, Africa must embrace technologies that enable it to produce more, better food with less effort.

Indeed, without the advances in molecular biology and other scientific fields that occurred in the second half of the twentieth century, African nations would be much worse off than they are now. Without this Green Revolution, which enabled developing nations to import cheaper grains and grow high-yield seed varieties, analysts estimate that crop yields in developing countries would have been $23.5 \%$ lower and prices between $35 \%$ and $66 \%$ higher in 2000 . Caloric intake would have dropped by up to $14.4 \%$, and the proportion of malnourished children would have increased by nearly $8 \%$. Put another way, the Green Revolution helped to raise the nutritional status of up to 42 million preschool children in developing countries (R. E. Evenson and D. Gollin Science 300, 758-762; 2003).

These tools were a great help to African nations in the previous century, but they are not sufficient to help Africa's agriculture survive what is coming: rising population and loss of productivity brought on by ecological disruptions such as environmental degradation and frequent droughts.

To weather these changes, African nations must be open to new biotechnology tools that allow farmers to grow crops that have even higher yields and a higher nutritional content, and which can withstand biological and physical stresses.

At present, only a few African countries are allowed to grow genetically modified (GM) crops, partly because of restrictive national biosafety policies that impose excessive regulatory barriers to the adoption of agricultural biotechnology. This must change.

For starters, African farmers need pestresistant GM cotton, which is already being cultivated in South Africa and Burkina Faso. These crops do not raise food-safety concerns, but their higher yields bring more disposable income to farmers, who can use that money for food crops. More countries should be planting herbicide-tolerant maize (corn), now in use in South Africa and Egypt, which reduces the need for weeding
- a significant benefit for African farmers, mostly women, who spend nearly 200 hours a year weeding a hectare of land.

Future innovations could bring even more benefits to African countries. For example, the Bill \& Melinda Gates Foundation of Seattle, Washington, is funding projects to produce crops that carry drought-tolerant genes.

Africa needs GM varieties of the blackeyed pea, a subspecies of the cowpea (Vigna unguiculata). The crop is often attacked by the insect Maruca vitrata, which causes US\$300 million in losses annually to smallscale farmers in Africa. Their only means of controlling the disease is using expensive pesticides, which cost Nigeria an estimated $\$ 500$ million a year. Their losses affect the world: the African continent currently produces nearly 5.2 million tonnes of the bean, accounting for nearly $70 \%$ of global output. Scientists at the Institute for Agricultural Research at Ahmadu Bello University in Zaria, Nigeria, have developed a GM variety containing insecticide genes from the bacterium Bacillus thuringiensis that can help to control the disease.

\section{DISEASE RESISTANCE}

Africa would also benefit greatly from having other disease-resistant crops. Bananas, for example, are a staple in Uganda, where adults often eat three times their body weight in bananas annually. But the banana is threatened by a bacterial disease known as Xanthomonas wilt, which causes more than $\$ 500$ million in crop losses annually. The disease also affects other African countries in the Great Lakes region. There are no resistant varieties of banana and no ways of treating them chemically. Ugandan scientists are working on creating a GM banana using genes from sweet pepper (Capsicum annuum) that helps to control Xanthomonas.

But even if Ugandan scientists can produce such a banana, the country's farmers are banned from growing it. Only 29 countries worldwide grow GM crops, and only three of those are African. But this is set to change in coming years, according to the non-profit organization International Service for the Acquisition of Agri-biotech Applications. Kenya has already adopted a law that permits the import of GM foods. This has opened the door for approving the cultivation of GM crops.

Critics of biotechnology are right to question its role in world agriculture - like other agricultural practices, biotechnology is not risk free. Concerns such as the transfer of GM genes to wild relatives and the development of resistance to pests need be taken seriously and kept under constant review. But addressing them requires greater investment in science and technology, not less. Such monitoring should be part of wider strategies to conserve biological 
diversity and protect human health; they should not be designed to discriminate against GM crops.

Furthermore, GM critics are wrong to conclude that because biotechnology does not solve all problems, it has no place in helping humanity to address long-term food needs. They often base their arguments on the presumption that most of the unintended consequences of genetic modification are likely to be negative, such as cases in which herbicide-resistant crops have spread to neighbouring lands. But we must look at the relative risks of all technologies, including the risks of not adopting the technology - such as how African nations would have suffered without the Green Revolution. According to a 2010 European Commission report on GM organisms, A Decade of EU-Funded GMO Research, based on 130 research projects spanning more than 25 years and involving more than 500 independent research groups, "biotechnology, and in particular GMOs, are not per se more risky than e.g. conventional plant breeding technologies".

The application of biotechnology has a number of unintended ecological benefits. For example, the adoption of GM crops has curbed the release of greenhouse-gas emissions by reducing the use of pesticides, which require energy to manufacture. It has also saved farmers from heavy exposure to these chemicals. In addition, the use of herbicide-tolerant crops enables farmers to cut back on the ploughing and weeding that releases carbon that would otherwise be sequestered in the soil. For 2009, it is estimated that biotech crops resulted in 17.6 billion kilograms of carbon dioxide sequestration and forgone release - the equivalent of removing 7.8 million cars from the road.

Solving world hunger will involve more than just producing more food. But excluding technological options that raise productivity will do more harm than good. The international community would be better served by taking a pragmatic approach that accommodates the best available technological options, rather than relying on ideological political positions that will put the world's most vulnerable people at risk. All technological options for meeting global food needs should therefore be on the table, including agricultural biotechnology.

Calestous Juma is the director of the Agricultural Innovation in Africa Project at Harvard Kennedy School, Cambridge, Massachusetts 02138, USA. He is author of The New Harvest: Agricultural Innovation in Africa (Oxford Univ. Press, 2011).

e-mail: calestous_juma@harvard.edu

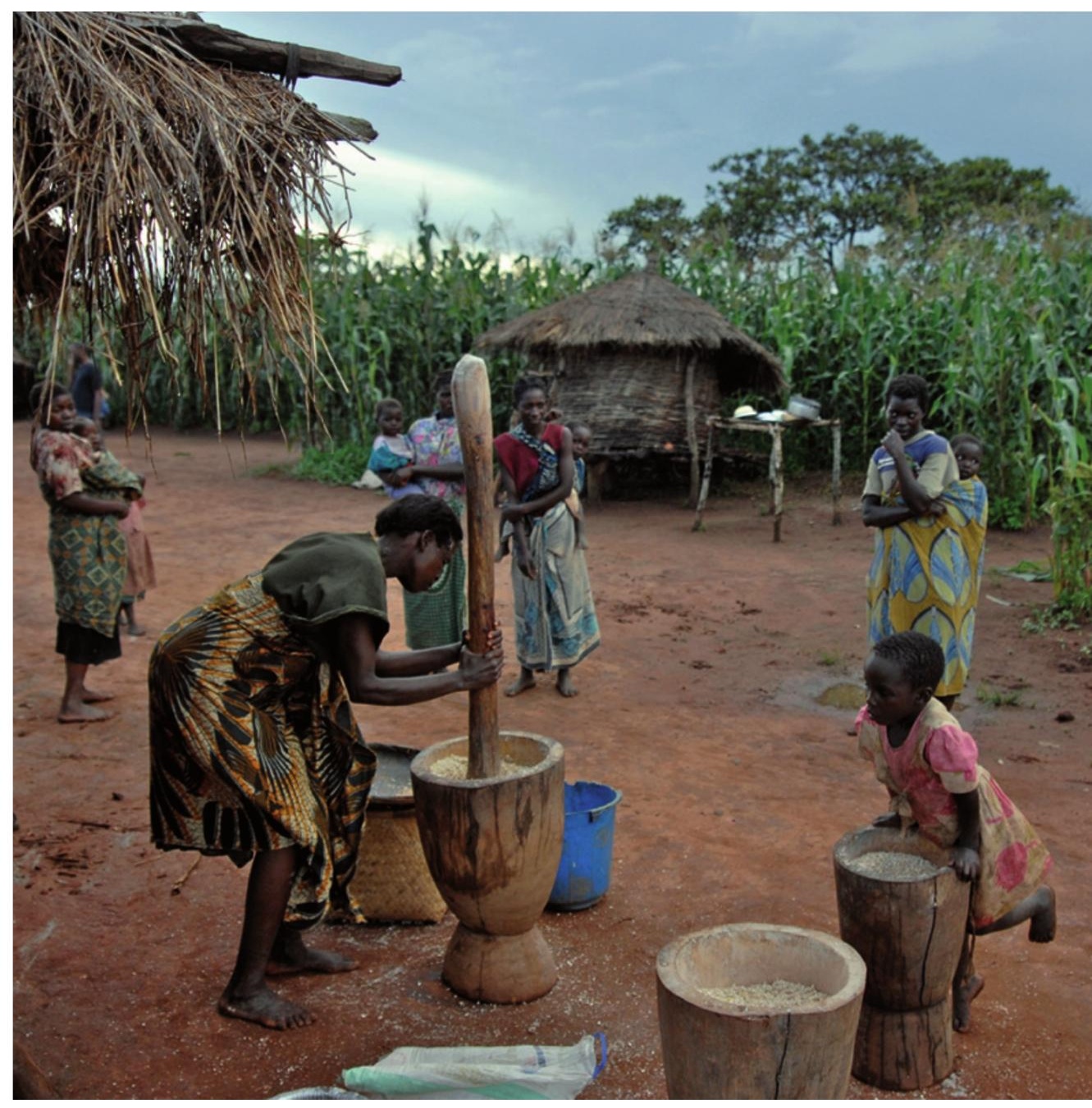

Giving power back to the people is key to ensuring the security of food supplies.

\section{Preventing hunger: Change economic policy}

Simply giving people food is not enough to prevent famine, says Peter Rosset. Instead, we need to overhaul the policies that have upended the food supply.

$\mathrm{T}$ The global food system is broken. The number of hungry and undernourished people in the world hovers at around 1 billion $^{1}$ and the past few years have seen both worldwide food riots as well as epidemics of obesity and diabetes.

Fifty years ago, the United Nations World Food Programme was formed to help reduce hunger. But its original mandate of handing out food was a band-aid at best - and can actually make people more vulnerable to hunger. We now have a food system that has been destroyed by decades of misguided policies that emphasized exports over feeding domestic populations and by runaway financial speculation. We now need to reverse those policies and fix what's broken.

According to the economic law of comparative advantage, agribusinesses should export the food, agrofuels and other products that are grown in a country, while cheaper foods are imported to feed the people. Any gaps in such a 'productionist' and 'free trade' system should then be covered by food aid, in which organizations such as the US Agency for International Development (USAID) and the World Food Programme 